\title{
Evaluating the Impact of Pharmacist Counselling for Asthmatic Children at Karbala Teaching Hospital for Children: An Interventional Prospective Study (Conference Paper) $)^{\#}$ \\ Mohammed Zuhair Mahdi ${ }^{*}, 1$ and Zinah M. Anwer
}

\# $9^{\text {th }}$ scientific conference conference sponsored by College of Pharmacy, University of Baghdad 25-26 August 2021 * Department of Clinical Pharmacy, College of Pharmacy, University of Baghdad, Baghdad, Iraq.

\section{Abstract}

Asthma is one of the most common chronic, non-communicable diseases affecting children worldwide. The estimated prevalence of pediatric asthma in Iraq is $15.8 \%$. Assessment and monitoring of asthma control can be done by a validated childhood asthma control test (C-ACT) and Asthma Control Test (ACT). Management plan of asthma must consider asthma counseling and education. Patient education accounts for $90 \%$ of success and this can be achieved by an active collaboration among health care providers. This study aimed to evaluate the impact of pharmacist counseling on asthma control in children. This was a prospective interventional educational study that recruited 92 asthmatic children aged 2-18 years old attended asthma and respiratory diseases out-patient clinic in Karbala Teaching Hospital for Children. The participants were interviewed face-to-face and counseled about asthma, given an educational booklet, examined their inhaler use technique and their ACT/C-ACT was calculated. The patients were followed up weekly for one month either by phone or face-to-face to assess asthma control; rescue medication used; signs and symptoms; inhalers use and; any other concerns about asthma. In the fourth week, ACT/C-ACT was calculated again. A total of 92 participants were involved. There was a significant increment in ACT/C-ACT after providing asthma counseling and weekly follow-up by the interventional pharmacist. The incorporation of pharmacists in the management plan of asthmatic children to provide asthma counseling and education about the proper use of inhalers will improve asthma control in children.

Keywords: Pediatric asthma, Patient education, Counseling, Childhood asthma control test.

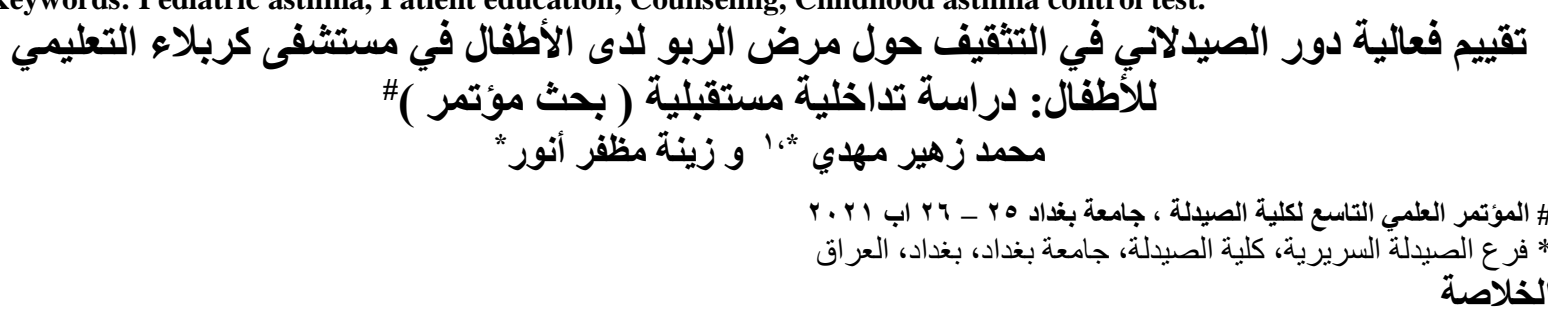

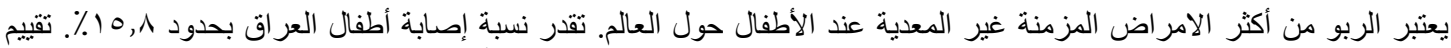

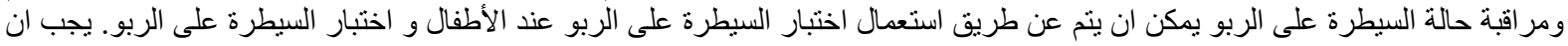

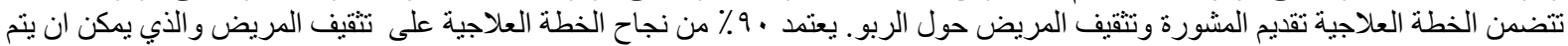

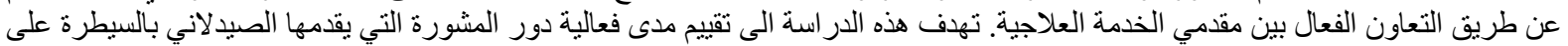

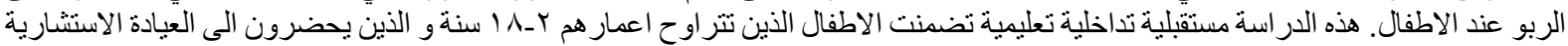

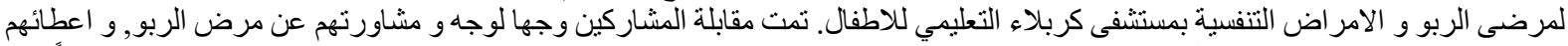

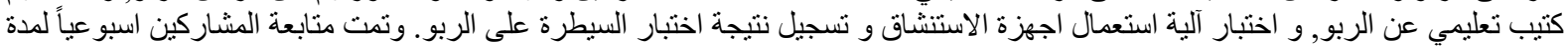

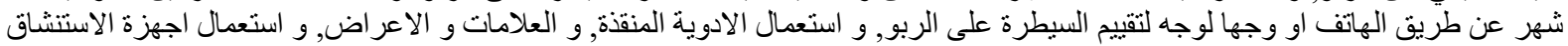

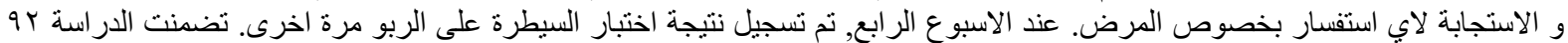

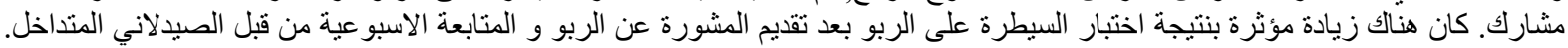

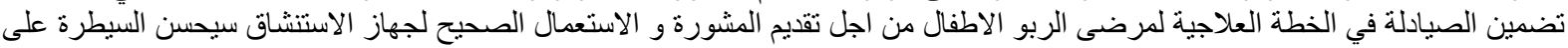
الربو عن الاطفال.

\section{Introduction}

Asthma is one of the commonest chronic non-communicable diseases of the lower respiratory tract in children ${ }^{(1)}$. Pediatric asthma prevalence ranged from $2.1 \%$ in Indonesia to $32.2 \%$ in the United Kingdom ${ }^{(2)}$. There are limited numbers of studies about asthma prevalence in Iraq. The estimated prevalence of pediatric asthma in Baghdad the capital of Iraq is $15.8 \%{ }^{(3)}$. Asthma should be questioned in any child with at least two of the classical symptoms which are cough, shortness of breath, wheezing, and chest tightness. These symptoms frequently develop after viral respiratory tract infection, after workout,

${ }^{1}$ Corresponding author E-mail: ilmilan22@yahoo.com

Received: 30/8/2021

Accepted: 20/10 /2021

Published Online First: 2022-1-12

Iraqi Journal of Pharmaceutical Science 
or experience of irritant allergen and subside in response to bronchodilators or anti-inflammatory therapy ${ }^{(4)}$.

A combination of Inhaled Corticosteroids (ICS) and a bronchodilator serve as a good option for persistent asthma management ${ }^{(5)}$.

The patient and the health care providers must have a mutual understanding about the asthma control (6). Asthma Control Test (ACT) and Childhood Asthma Control Test (C-CAT) are validated and two of the numerical tests used to assess asthma control in children aged 12 years and older and 4-11 years old, respectively ${ }^{(7,8)}$.

Notwithstanding the innovations in health care systems and pharmacological management of asthma, its control is still below the expectation. It is estimated that the prevalence of poor asthma control among the pediatric age group is $46 \%{ }^{(9)}$. The main reasons for that are: I) modest medication use; II) poor medication compliance; III) inappropriate inhalation technique; IV) exposure to triggers and; V) parents' phobia of steroids ${ }^{(10,11)}$.

Pharmaceutical care is a pharmacist's involvement to optimize the use of medications by individuals. Pharmaceutical care may improve adherence, the clinical effectiveness of therapy, and improve the health-related quality of life ${ }^{(12)}$. Time spent by physicians with their asthmatic patients is usually limited as well as the available resources for effective counseling and education ${ }^{(13)}$. Some studies showed that the health care provider assesses the inhalation technique in only $5 \%$ of visits (14). Therefore, delegating this task to other health care providers may be a good alternative in providing efficient counseling and education. Pharmacists, by their position as a part of health care providers and their contribution as the first and accessible interface, may play a significant role by delivering asthma counseling and inhalers use technique after getting the proper recommendations by the physicians (10,15,16). Management of asthma may depend $90 \%$ on education and only $10 \%$ on medication (11). Inspiring health care providers, asthmatic children, and their parents to share their concerns about asthma and medication use will facilitate the communication process and diminish the barriers ${ }^{(17)}$

Pharmacist intervention by providing asthma counseling had been shown to bring better asthma control in terms of higher ACT/ C-ACT scores, reduced number of exacerbation and systemic steroid use, and better quality of life ${ }^{(18,19)}$. Pharmacist integration with the physician to reassure the management of asthmatic patients according to guidelines presented better asthma control ${ }^{(20)}$. The pharmacist-led intervention also brought cost-effectiveness and increased qualityadjusted life years ${ }^{(21)}$.

This study aimed at evaluating the impact of pharmacist counseling on asthma control in children following Global Initiative for Asthma (GINA) 2020 regarding patient education and involvement in the management plan.

Methods

The study started on the first of January 2021 and ended on the first of May 2021 with a single weekly visit to Karbala Teaching Hospital for Children. The visits were on Tuesday, which is the day already specified for the asthmatic patient to visit asthma and respiratory diseases outpatient clinic on regular basis to check their asthma and refill their medication.

Study design

This was a prospective interventional educational study that was conducted at Karbala Teaching Hospital for children. It is the main and only hospital for children at Karbala where all the referral of pediatric patients occurs. The study was approved by the Ethical and Scientific Committee of the College of Pharmacy - University of Baghdad and followed the principles of Helsinki declaration regarding such sort of studies (22). Approval to conduct the study had been taken from Karbala Teaching Hospital for Children managerial board verbally.

\section{Sample size}

The sample size was determined using the Raosoft platform for sample size calculation ${ }^{(23)}$. An accepted margin error of 5\% will result in 377 participants needed to conduct the study, however, the sample size couldn't be collected due to missing data regarding the actual number of asthmatic children who keep regular visits at asthma and respiratory disease outpatient clinic and reduced number of visits to the hospital due to Corona Virus Disease 2019 (COVID-19) pandemic worldwide. So that, a convenient sample of patients who were interviewed during the timetable of the study and met the inclusion criteria were involved.

\section{Patients}

The patients were first diagnosed with asthma by a specialized physician after paying nominal costs for the specialist's consultation and medications. A sample of those patients had been referred to the interventional pharmacists to be recruited in the study if they met the inclusion criteria. Those who did meet the inclusion criteria underwent simple counseling about asthma and inhaler device techniques. The recruited participants aged 4-12 gave their assents and their parents' consent was taken verbally to participate in an asthma educational program and follow up weekly either by phone or face-to-face for one month in an attempt to improve their asthma control and increase their awareness about the disease.

Inclusion criteria were: age 2-18 years old; asthmatic patients who used controller therapy; regular attendees at asthma and respiratory diseases outpatient clinic; Iraqi and resident at Karbala; able to understand and complete ACT $\backslash \mathrm{C}$-ACT; living 
with anyone who can read and write; have the intent to improve his her asthma control and; available for following up by phone or face-to-face.

Exclusion criteria were: patients with any other chronic diseases, pneumonia and missed the weekly follow up at any week.

\section{Asthma control assessment}

Asthma control had been assessed by ACT for children 12-18 years old and C-ACT for children aged 2-11 years old (Appendix?). ACT is a validated numerical test that consists of 5 items to be answered by the patient and then a summation of items represents the total score that ranges 5-25. Score less than 19 means the asthma is not well controlled. CACT is also a validated numerical test that consists of two divisions. The first division includes four questions to be answered by the child or parents about the symptoms and the reliever medication used. The second division includes three questions related to patient self-assessment of control in the past four weeks. The score of each item was summed to provide a total score of $0-27$ with a higher score means better control. ACT \C-ACT was calculated at the first face-to-face interview as a baseline and four weeks after the follow-up.

\section{Data collection}

A face-to-face interview taking about 10 minutes was conducted either with children aged 1218 years old or the parents for those whose age is 211 years old to collect data by a sheet especially designed for the study which contains four aspects: patients' data; asthma characteristics; inhaler devices technique checklist; weekly follow-up checklist; and ACT\C-ACT score. The weekly follow-up checklist had been filled during the follow-up period.

\section{Asthma counseling}

After collecting data, the participants or interventional pharmacist for their knowledge about asthma by simple questions (e.g. asthma definition, causes, types of medication, etc.). This assessment provides a good insight into the extent of asthma counseling to be given to them in a 15-minute interview. The interview stressed on asthma definition, signs and symptoms, causes, triggers, inhaler technique, the different types of inhalers, and which one should be used regularly, and which one on need. A short video clip on YouTube had been used to show the proper use of different types of inhalers as well as a physical tutorial by one of the interventional pharmacists for participants who use inhalers ${ }^{(24)}$.

\section{Follow up}

After the completion of the face-to-face interview, the participants aged 12 years old and older were followed up weekly by phone calls or face to face meetings with them directly for one month, participants aged 11 years and younger were followed up with their parents either by phone or face-to-face meetings for the same period. Each week they were asked if there were any symptoms according to a predefined checklist presented in appendix A. At the end of the fourth phone call, the patient underwent an ACT \C-ACT again to evaluate the impact of the intervention done by the interventional pharmacists.

\section{Statistical analyses}

Descriptive statistics (means, standard deviation, frequencies, and percentages) were conducted for all participants. Data were analyzed using Statistical Package for the Social Sciences (SPSS) software (version 24). Paired samples T-test was used to measure the difference in ACT $\backslash C$-ACT scores of the asthmatic children due to pharmacist intervention. their parents were assessed roughly by the

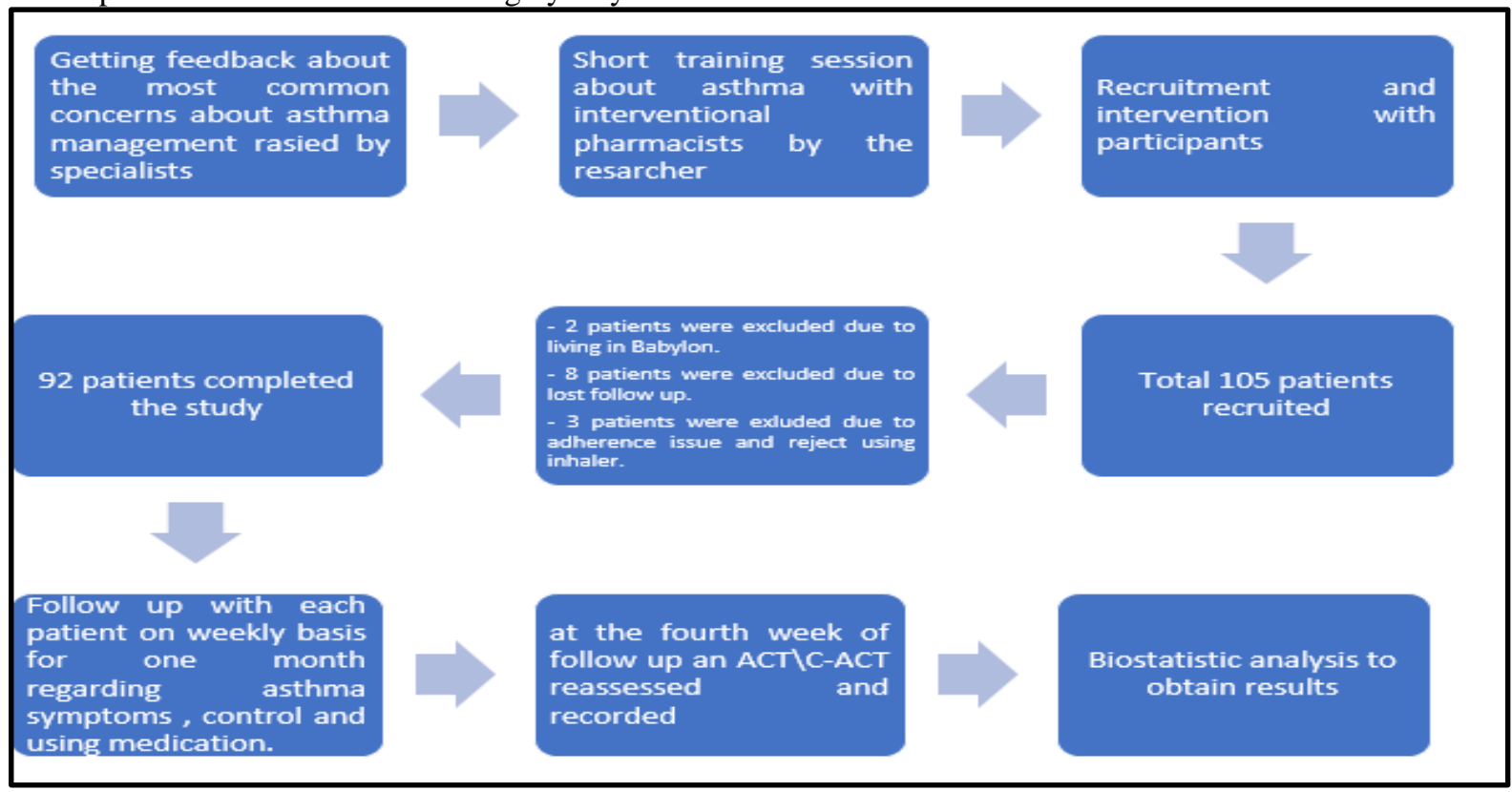

Figure 1. The flowchart of the study process 


\section{Results}

One hundred and five participants were enrolled in the study. Thirteen participants were excluded ( 2 participants were excluded due to living outside Karbala province, 8 participants were excluded due to missed follow-up, and 3 participants were excluded due to adherence to medication and rejection of the use of inhalers). Ninety-two participants who met the inclusion criteria in the study remained. The interventional pharmacist provided asthma counseling to the child's parent mostly $(67.4 \%)$. The majority of participants were male $(58.7 \%)$. More than three-quarters of the consulted parents had secondary school or lower education with low or middle incomes (Table 1).

Table 1. The characteristics of the participants/guardian of the participants and their average pre and post ACT $\backslash C$-ACT score.

\begin{tabular}{|c|c|c|c|c|}
\hline Characteristic & Subcategories & $\mathrm{N}(\%)$ & $\begin{array}{c}\text { Pre ACT } \backslash C-A C T \\
\text { Score }\end{array}$ & $\begin{array}{c}\text { Post ACT } \backslash C-A C T \\
\text { Score }\end{array}$ \\
\hline \multirow[t]{2}{*}{ Patient gender } & Female & $38(41.30)$ & 16.16 & 21.03 \\
\hline & Male & $54(58.70)$ & 15.59 & 22.09 \\
\hline \multirow[t]{3}{*}{ Parent income } & Low & $41(44.60)$ & 15.54 & 21.90 \\
\hline & Middle & $42(45.70)$ & 15.95 & 21.69 \\
\hline & High & $9(9.80)$ & 16.56 & 20.33 \\
\hline \multirow[t]{3}{*}{ Parent education } & $\begin{array}{c}\text { Illiterate - Primary } \\
\text { school }\end{array}$ & $\begin{array}{c}47 \\
(51.10) \\
\end{array}$ & 15.77 & 21.79 \\
\hline & Secondary school & $\begin{array}{c}31 \\
(33.70)\end{array}$ & 15.55 & 21.58 \\
\hline & College or higher & $\begin{array}{c}14 \\
(15.20)\end{array}$ & 16.64 & 21.36 \\
\hline \multirow[t]{2}{*}{ Consulted person } & Child & $\begin{array}{c}30 \\
(32.60) \\
\end{array}$ & 16.77 & 20.63 \\
\hline & Parent & $\begin{array}{c}62 \\
(67.40) \\
\end{array}$ & 15.37 & 22.15 \\
\hline
\end{tabular}

The average age of the participants was 9.34. There was an increment in ACT\C-ACT score after interventional pharmacist counseling (Table 2).

Table 2.The descriptive characteristics of the participating patients

\begin{tabular}{||l|c|c|c|c|c||}
\hline \multicolumn{1}{|c|}{ Characteristic } & $\mathrm{N}$ & $\begin{array}{c}\text { Minimu } \\
\mathrm{m}\end{array}$ & $\begin{array}{c}\text { Maximu } \\
\mathrm{m}\end{array}$ & Mean & $\begin{array}{c}\text { Std. } \\
\text { Deviation }\end{array}$ \\
\hline Age (year) & 92 & 2.0 & 18.0 & 9.34 & 3.83 \\
\hline Height $(\mathrm{cm})$ & 92 & 84.0 & 174.0 & 131.64 & 20.52 \\
\hline Weight $(\mathrm{Kg})$ & 92 & 11.5 & 88.0 & 33.82 & 15.65 \\
\hline Pre-counseling ACT*IC-ACT $* *$ Score & 92 & 5.0 & 26.0 & 15.83 & 4.82 \\
\hline Post-counseling ACT*IC-ACT $* *$ Score & 92 & 10.0 & 27.0 & 21.65 & 3.54 \\
\hline Body Mass Index (BMI) & 92 & 8.31 & 32.32 & 18.46 & 4.01 \\
\hline
\end{tabular}

* ACT = Asthma Control Test.

** C-ACT $=$ Childhood Asthma Control Test

Sixty-six percent of the participants had uncontrolled asthma at baseline according to their

ACT $\backslash C$-ACT score compared to eighty-four percent after interventional pharmacist counseling (Table 3).

Table 3. The descriptive characteristics of asthma control and socioeconomic status

\begin{tabular}{||c|c|c|c|c||}
\hline $\begin{array}{c}\text { Socioeconomic } \\
\text { Status }\end{array}$ & $\begin{array}{c}\text { \% of Uncontrolled } \\
\text { asthma }\end{array}$ & $\begin{array}{c}\text { \% of Controlled } \\
\text { asthma }\end{array}$ & $\begin{array}{c}\text { \% of Uncontrolled } \\
\text { asthma }\end{array}$ & $\begin{array}{c}\text { \% of Controlled } \\
\text { asthma }\end{array}$ \\
\hline High & $\mathbf{5 . 4 3}$ & $\mathbf{4 . 3 5}$ & $\mathbf{2 . 1 7}$ & $\mathbf{7 . 6 0}$ \\
\hline Moderate & $\mathbf{3 2 . 6 1}$ & $\mathbf{1 1 . 9 6}$ & $\mathbf{7 . 6 3}$ & $\mathbf{3 9 . 1 3}$ \\
\hline Low & $\mathbf{2 8 . 2 6}$ & $\mathbf{1 7 . 3 9}$ & $\mathbf{5 . 4 3}$ & $\mathbf{3 8 . 0 4}$ \\
\hline Total & \multicolumn{3}{|c|}{} \\
\hline
\end{tabular}


The majority (61 out of 92) of asthmatic children had familial atopic diseases including asthma and eczema (40.2\%), asthma alone (18.5\%), allergic rhinitis $(3.3 \%)$, eczema alone $(2.2 \%)$, and allergic rhinitis and asthma (2.2\%) (Figure 2).

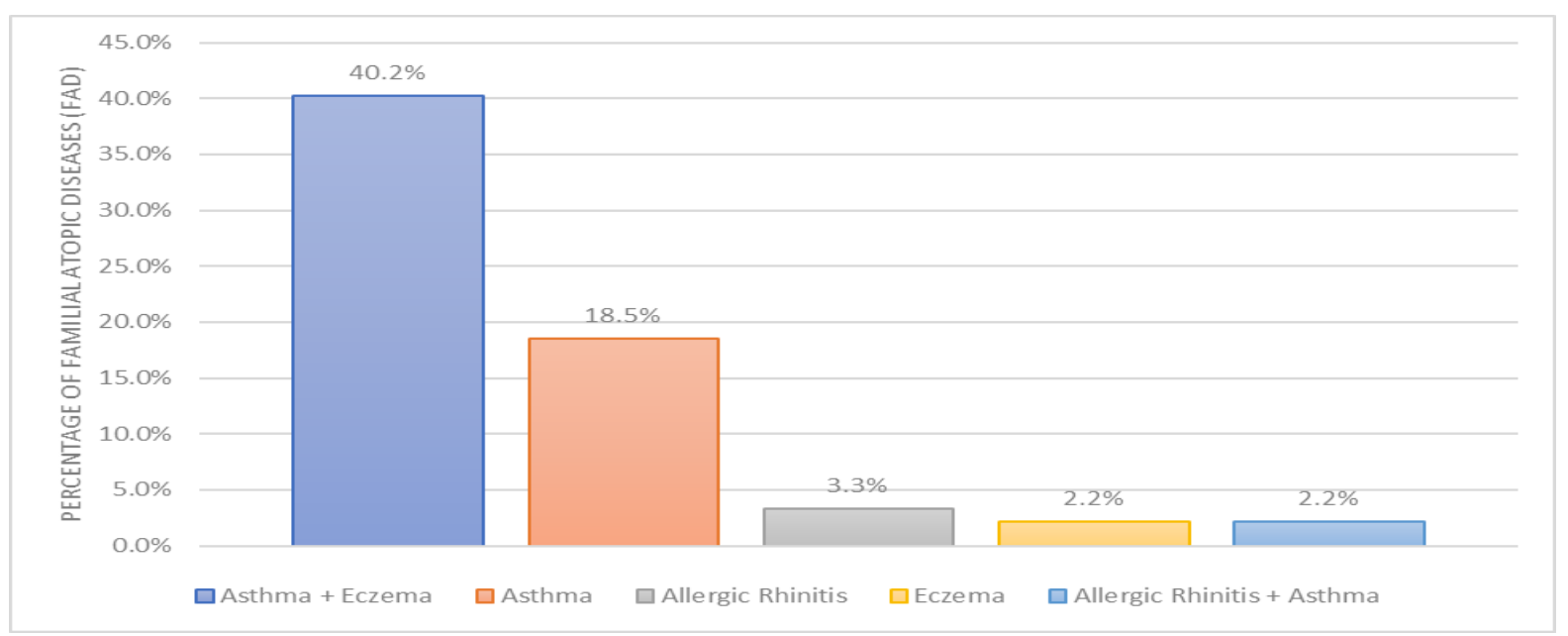

Figure 2. Percentage of Familial Atopic Diseases (FAD) among Participants

The interventional pharmacist check listed eight different steps of instructions about the proper use of asthma inhalers. The most common incorrect technique steps were the eighth $(44 \%)$ and fifth $(62 \%)$ steps respectively (Figure 3$)$.

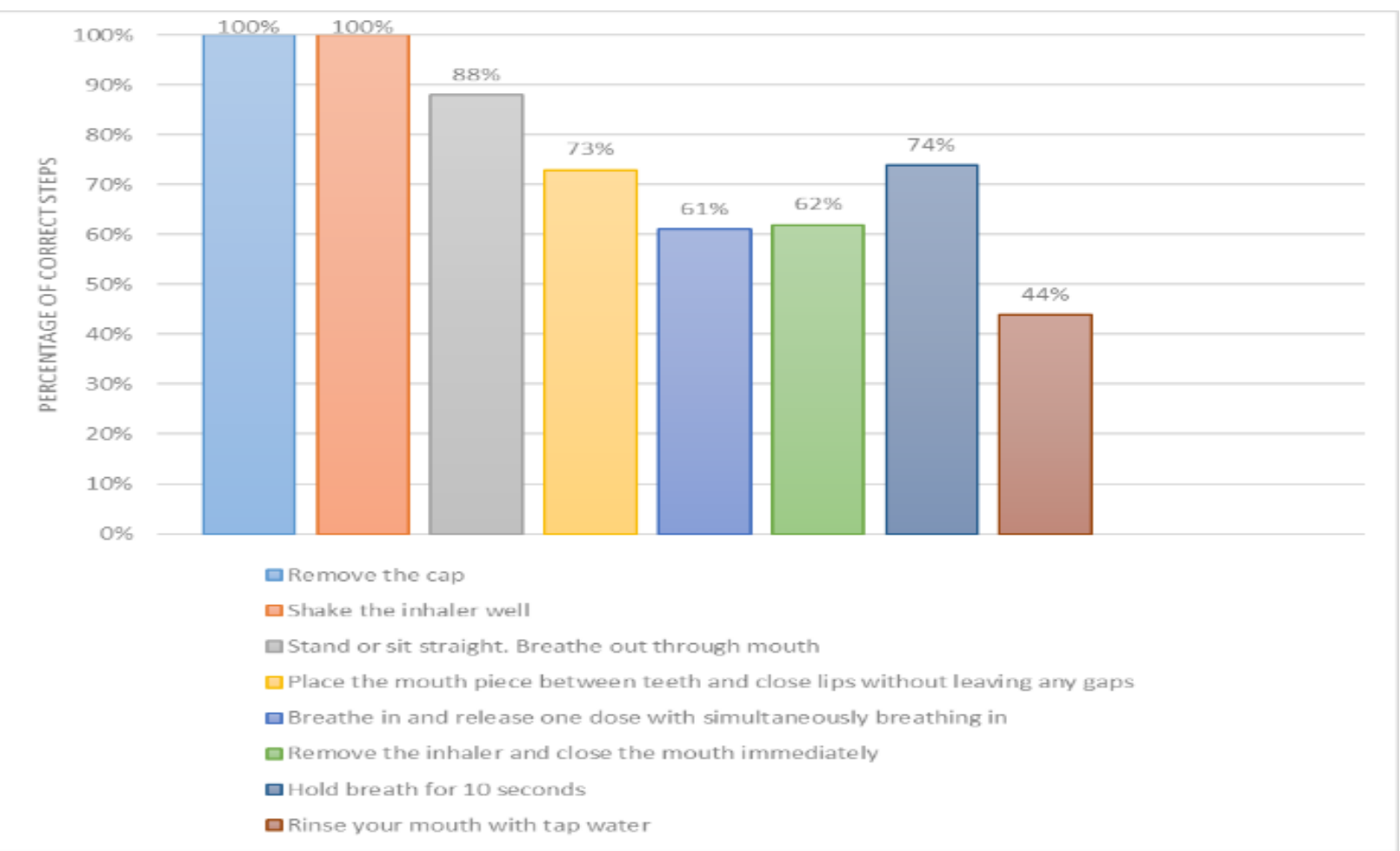

\section{Figure 3. Steps of an Inhaler Technique error}

There was a significant ( $\mathrm{P}$-value $<0.05)$ increment in the ACT $\backslash \mathrm{C}$-ACT score after pharmacist counseling to the asthmatic children or their parents about asthma definition, symptoms, types of medication, the proper use of asthma inhalers, and other educational information related to asthma. (Figure 4) 


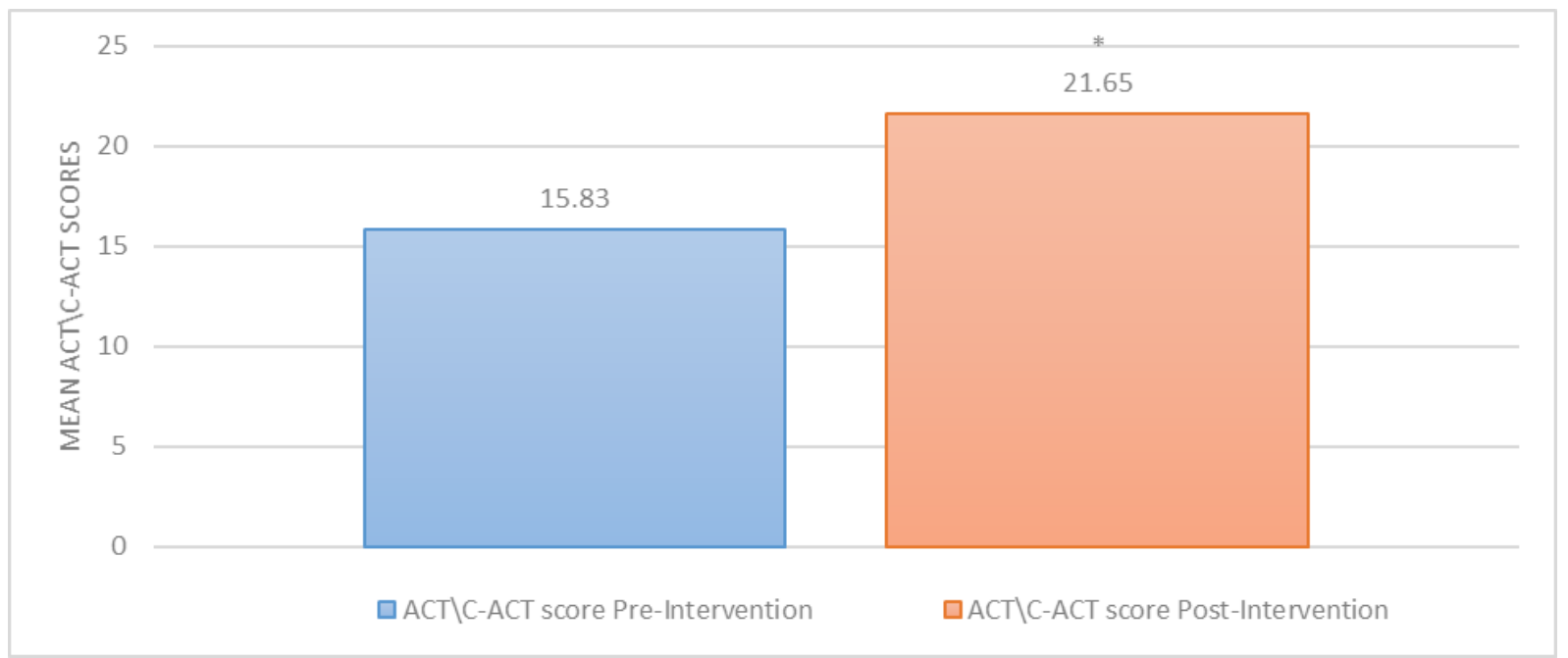

Figure 4. The increment in ACT\C-ACT score after interventional pharmacist counseling *Significant difference (P-value< 0.05$)$ according to paired samples T-test.

There was a significant difference in the pharmacist intervention according to the person who increment in ACT\C-ACT scores due to the received the counseling (child vs parent) (Figure 5)

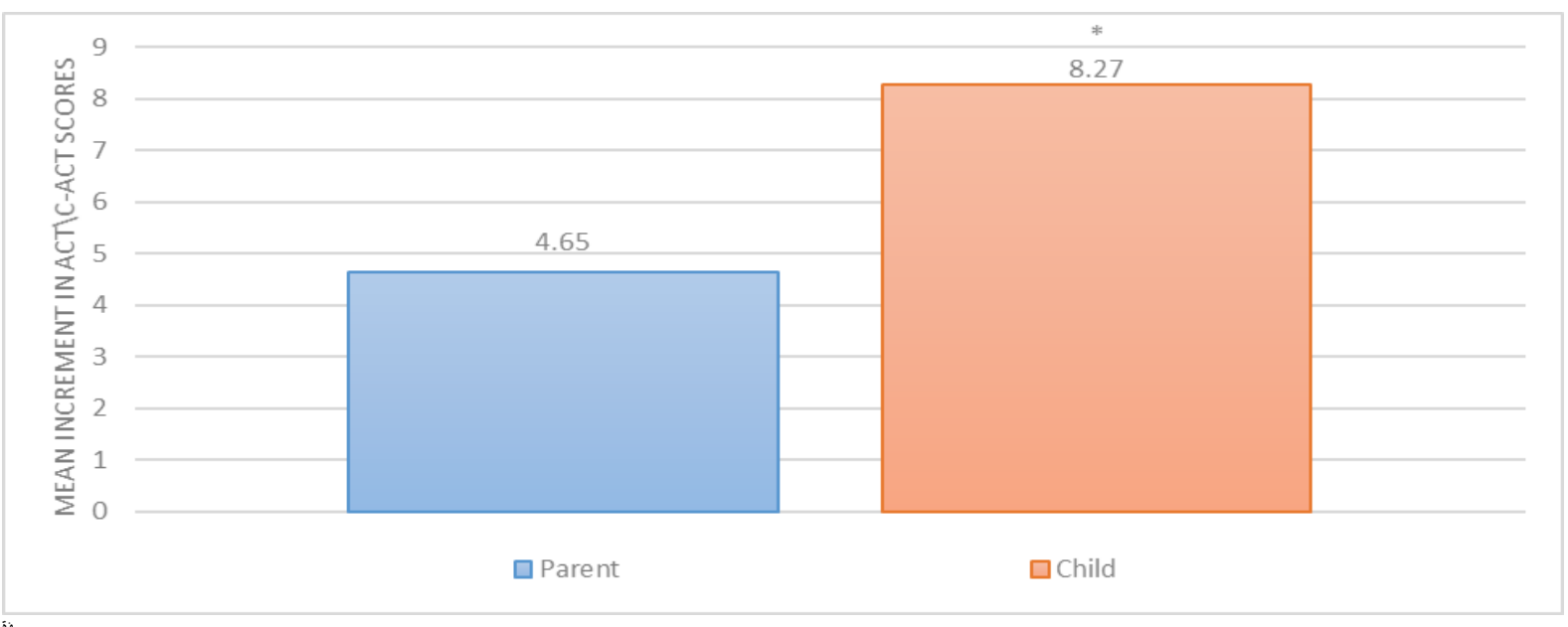

Figure 5. Mean increment in ACT\C-ACT scores after pharmacist intervention according to the person who received counseling

*Significant difference $(\mathrm{P}$-value $<0.05)$ according to Independent $\mathrm{t}$-test

\section{Discussion}

The encumbrance of childhood asthma is still increasing worldwide despite the international efforts to manage it according to GINA. There are many reasons which could contribute to reduced control including poor patient education, availability of medication, cultural beliefs and challenges in applying guidelines locally ${ }^{(25)}$.

This study represents the first prospective interventional educational study for asthmatic children at Karbala, Iraq. It is a patient-oriented study to evaluate the impact of pharmacist counseling on asthma control in children by increasing awareness about asthma knowledge like definition, causes, triggers, signs and symptoms, types of medication, and the proper use of the inhalers.
Most of the study participants were male $(58.7 \%)$ which comes in line with a review article that showed the prevalence of asthma in children is about two-third for boys and one-third for girls with increasing prevalence in girls after adolescence suggesting a role of sex hormone and environmental exposure $^{(26)}$.

In this study, most boys were playing and socializing with their siblings in school, neighborhoods, and other places like accompanying their parents at their work which may put them at a higher risk of environmental exposure to asthma triggers while girls had a lower chance of such exposure. These explanations had been made upon the interviews made with parents during data collection.

The majority of study participants $(90 \%)$ was low to medium income families whose children 
had asthma which appears to be similar to that found by Davies et al. that stated the prevalence of asthma is greater in low-income families who may have a lower chance of having a good education and optimal academic career ${ }^{(27)}$. A systemic review by Didsbury et. al mentioned that children with a chronic disease like asthma and with low income had reduced quality of life when compared to their richer peers ${ }^{(28)}$. This study was conducted at a governmental public hospital which is mainly visited by patients with low to medium socioeconomic status to have their medical visits, investigations, and medications at nominal costs while high socio-economic status patients may prefer to visit private clinics and hospitals to get better quality of service at surely, higher costs.

Asthma counseling provides better asthma control even for those with limited socioeconomic status as the study showed by the reduction occurred in the percentage of uncontrolled asthma after counseling.

The educational degree of parents also contributes to the asthma control level, a Lebanese study showed that children whose parents had a low education level are at a greater risk for uncontrolled asthma ${ }^{(29)}$. In this study, half of the participants are either uneducated or have a primary education which appears to be correlated with the poor ACT \C-ACT scores before interventional pharmacist's counseling. Another study in Sweden showed that higher parental education is positively correlated with asthma control of their children ${ }^{(30)}$. In Brazil, Roncada C et al published a study in 2018 that examined the association between asthma control and parental knowledge of asthma and found that parents with insufficient asthma knowledge scores had a bad impact on their children's asthma control $^{(31)}$.

Atopic diseases are considered one of the main risk factors for the development of asthma in these children with the main percentage for those who have a familial history of asthma and eczema. This finding comes in line with a cross-sectional study that included 1601 participants in the Kingdom of Saudi Arabia that showed a significant association between familial atopic diseases and the development of asthma in children aged 7-12 years old ${ }^{(32)}$. Other similar results were found in a survey conducted in China in 2014 which showed that atopy is the major risk factor for asthma development ${ }^{(33)}$. Atopic diseases running in families can be used to provide primary prevention for the development of asthma or wheeze in young children with breastfeeding in the first month taking the priority as a preventive measure ${ }^{(34-36)}$

Inappropriate inhaler techniques were an important issue with asthmatic patients and revisiting that on regular basis with the patient is a key factor for improving their asthma control $(11,37,38)$ - Addressing the specific steps at which the techniques are incorrect and ensure proper counseling and education about it results in better asthma control ${ }^{(18,39)}$. Simultaneous actuating and breathing in and rinsing mouth after completion were the two commonest steps that appeared to be incorrect techniques and need more attention during dispensing inhaler devices for asthmatic children since pharmacists are usually accessible and represent the only one who are responsible for medication dispensing.

The mean ACT \C-ACT score was 15.83 at baseline which reflects poor control of asthma despite the optimal medication dispensed for them according to the local practice at Karbala Teaching Hospital for Children and availability of medication. Interventional pharmacist counseling provided greater ACT \C-ACT score that is 21.65 after completing one month of weekly follow up that indicates better control of asthma.

The pre-post ACT\C-ACT increment was significant in this study which shows the importance of pharmacists counseling with asthmatic children to enhance their knowledge as well as technique of inhaler use. Such results had been seen in other studies in Jordan and Nepal about asthma overview and inhaler technique ${ }^{(19,40,41)}$.

The study showed a statistically significant improvement of asthma control according to ACT \C-ACT score due to the weekly follow-up check that had been made by the interventional pharmacists. This comes in line with a journal article by Mehuys et al. that showed an improvement in the ACT after pharmacist counseling with the patient about asthma definition, triggers, and medication used to manage it as a complementary process of asthma control ${ }^{(42)}$, however; it needs to be studied extensively in future to get a clear image if the better control was consistent or only during the follow-up period especially that the assessment tool is subjective rather than objective.

\section{Conclusion}

Pharmacists-led,Patient-focused counseling about asthma and its medication will provide better control of symptoms and hence, a better quality of life. This will be a complementary process for the physician diagnosis and prescription of medication. We need more studies that focus on having welltrained pharmacists who can provide smooth counseling and eliciting the patient's hidden concerns and barriers for using the medication regularly and properly.

\section{Limitations}

1. Sample size: the reasonable sample size for such a study could not be obtained due to COVID-19 restrictions when the parents prefer not to bring their children with them.

2. Medication adherence validation: we couldn't perform the Morisky scale for patient's adherence due to the short time 
invested with the patient in counseling and education about their asthma medication.

3. Asthma severity: the severity of asthma was not addressed in this study which may affect the ACT $\backslash \mathrm{C}$-ACT scores.

\section{Acknowledgment}

I'd like to acknowledge the unlimited support by Dr. Hayder Al-Mudhafer who was the physician responsible for diagnosis and referral of asthmatic children as well as the dedicated efforts of interventional pharmacists who participate in this study and followed up with patients, namely, Sarah Shaalan, Baraa Fadheel, Zainab Hazim and Riyam Qasim

\section{References}

1. Papi A. Asthma. Lancet. 2018;391(10122):783800.

2. Pearce N. Worldwide trends in the prevalence of asthma symptoms: Phase III of the International Study of Asthma and Allergies in Childhood (ISAAC). Thorax. 2007;62(9):757-65.

3. Al-Thamiri D. Asthma prevalence and severity among primary-school children in Baghdad. East Mediterr Heal J = La Rev sante la Mediterr Orient = al-Majallah al-sihhiyah li-sharq al-mutawassit. 2005;11(1-2):79-86.

4. Fitzgerald JM. Canadian Thoracic Society Asthma Management Continuum - 2010 Consensus Summary for children six years of age and over, and adults. Can Respir J. 2010;17(1):15-24.

5. Jasim AL. Assessing the response of a sample of iraqi asthmatic patients to different medication regimens. Iraqi J Pharm Sci. 2020;29(1):1119-26.

6. Aroni R. Enhancing validity: what counts as an asthma attack? J Asthma. 2004 Oct;41(7):729-37.

7. Nathan RA. Development of the asthma control test: A survey for assessing asthma control. J Allergy Clin Immunol [Internet]. 2004 Jan 1 [cited 2021 Sep 25];113(1):59-65. Available from: http:// www. Jacionline .org/ article / S009167490302270X/fulltext

8. Liu AH. Development and cross-sectional validation of the Childhood Asthma Control Test. J Allergy Clin Immunol [Internet]. 2007 Apr 1;119(4):817-25. Available from: http:// www. Jacionline .org / article/ S0091674907001674 /fulltext

9. Stanford RH. Predictors of uncontrolled asthma in adult and pediatric patients: Analysis of the asthma control characteristics and prevalence survey studies (ACCESS). J Asthma [Internet]. 2010 Apr;47(3):257-62. Available from: https://pubmed.ncbi.nlm.nih.gov/20210612/

10. Fathima $M$. The role of community pharmacists in screening and subsequent management of chronic respiratory diseases: A systematic review. Pharm Pract (Granada) [Internet]. 2013 [cited 2021 May
5];11(4):228-45. Available from: https://pubmed.ncbi.nlm.nih.gov/24367463/

11. Fink JB. Problems with inhaler use: a call for improved clinician and patient education. Respir Care. 2005 Oct;50(10):1360-5.

12. Swieczkowski D. The pharmaceutical care in asthma - Polish and global perspective. Adv Respir Med. 2016;84(3):225-31.

13. Cabana MD. Selective provision of asthma selfmanagement tools to families. Pediatrics [Internet]. 2008 Apr;121(4). Available from: https://pubmed.ncbi.nlm.nih.gov/18381518/

14. Sleath B. Provider demonstration and assessment of child device technique during pediatric asthma visits. Pediatrics [Internet]. 2011 Apr [cited 2021 May 7];127(4):642-8. Available from: https://pubmed.ncbi.nlm.nih.gov/21444594/

15. Tilly-Gratton A. Physician agreement regarding the expansion of pharmacist professional activities in the management of patients with asthma. Int J Pharm Pract. 2017;25(5):335-42.

16. Armour CL. Using the community pharmacy to identify patients at risk of poor asthma control and factors which contribute to this poor control. J Asthma [Internet]. 2011 Nov [cited 2021 May 5];48(9):914-22. Available from: https://pubmed.ncbi.nlm.nih.gov/21942306/

17. Sleath B. Child and caregiver reported problems in using asthma medications and question-asking during paediatric asthma visits. Int J Pharm Pract. 2014;22(1):69-75.

18. Almomani BA. The effectiveness of clinical pharmacist's intervention in improving asthma care in children and adolescents: Randomized controlled study in Jordan. Patient Educ Couns [Internet]. 2017;100(4):728-35. Available from: http://dx.doi.org/10.1016/j.pec.2016.11.002

19. Basheti IA. Inhaler technique education and asthma control among patients hospitalized for asthma in Jordan. Saudi Pharm J [Internet]. 2018;26(8):1127-36. Available from: https://doi.org/10.1016/j.jsps.2018.06.002

20. De Vries TW. Effect of a minimal pharmacy intervention on improvement of adherence to asthma guidelines. Arch Dis Child. 2010;95(4):302-4.

21. Tinelli M. Novel pharmacist-led intervention secures the minimally important difference (MID) in Asthma Control Test (ACT) score: Better outcomes for patients and the healthcare provider. BMJ Open Respir Res. 2018;5(1):1-9.

22. Review C. World Medical Association Declaration of Helsinki: ethical principles for medical research involving human subjects. J Am Coll Dent. 2014;81(3):14-8.

23. Raosoft.com. 2004. Sample Size Calculator by Raosoft, Inc.. [online] Available at: <http:// www. raosoft. Com /samplesize.html $>$ [Accessed 15 December 2020]. 
24. Proper use of different types of inhalers (Arabic video) [Internet]. Available from: https:/ /www. Youtube .com/ watch?v=IcS-AMn4dCc

25. Serebrisky D. Pediatric asthma: A global epidemic. Ann Glob Heal. 2019;85(1):1-6.

26. Almqvist $C$. Impact of gender on asthma in childhood and adolescence: A GA 2LEN review. Allergy Eur J Allergy Clin Immunol. 2008;63(1):47-57.

27. Davis DW. Educational interventions for childhood asthma: a review and integrative model for preschoolers from low-income families. Pediatr Nurs. 2011;37(1):31-8.

28. Didsbury MS. Socio-economic status and quality of life in children with chronic disease: A systematic review. J Paediatr Child Health. 2016 Dec;52(12):1062-9.

29. Hallit S. Validation of asthma control questionnaire and risk factors affecting uncontrolled asthma among the Lebanese children's population. Respir Med. 2017 Jan;122:51-7.

30. Strömberg Celind F. Higher parental education was associated with better asthma control. Acta Paediatr Int J Paediatr. 2019;108(5):920-6.

31. Roncada C. Levels of knowledge about asthma of parents of asthmatic children. Einstein (Sao Paulo). 2018;16(2):eAO4204.

32. Al-frahy A. Family history of atopy as a risk factor for childhood asthma and allergic disorders in Saudi Arabia. J Dis Glob Heal. 2016;8(1):1825.

33. Tang SP. Trends in prevalence and risk factors of childhood asthma in Fuzhou, a city in Southeastern China. J Asthma. 2015;52(1):10-5.

34. Huang C-C. Risk factors for asthma occurrence in children with early-onset atopic dermatitis: An 8year follow-up study. Pediatr Allergy Immunol
[Internet]. 2018 Mar 1 29(2):159-65. Available from: https:// onlinelibrary .wiley. com/ doi/ full /10. $1111 /$ pai. 12835

35. Wahn U. Childhood risk factors for atopy and the importance of early intervention. J Allergy Clin Immunol [Internet]. 2001 Apr 1;107(4):567-74. Available from: http:// www. Jacionline .org /article / S0091674901607309/fulltext

36. Crestani E. Parental asthma as a risk factor for the development of early skin test sensitization in children. J Allergy Clin Immunol [Internet]. 2004 Feb 1;113(2):284-90. Available from: http:// www. jacionline. org/ article/ S009 1674903026 241 / fulltext

37. V G. Misuse of corticosteroid metered-dose inhaler is associated with decreased asthma stability. Eur Respir J [Internet]. 2002 19(2):24651. Available from: https:// pubmed. ncbi. nlm. nih.gov/11866004/

38. Axtell S. Effectiveness of various methods of teaching proper inhaler technique: The importance of pharmacist counseling. J Pharm Pract. 2017;30(2):195-201.

39. Gemicioglu B. Investigation of knowledge of asthma and inhaler devices in pharmacy workers. J Asthma. 2014;51(9):982-8.

40. Yadav A. Pharmacist led intervention on inhalation technique among asthmatic patients for improving quality of life in a private hospital of Nepal. Pulm Med. 2019;2019.

41. Basheti IA. Role of the pharmacist in improving inhaler technique and asthma management in rural areas in Jordan. Clin Pharmacol Adv Appl. 2019;11:103-16.

42. Mehuys E. Effectiveness of pharmacist intervention for asthma control improvement. Eur Respir J. 2008;31(4):790-9. 